\section{(- OPEN ACCESS}

\title{
Efficacy of 4-year treatment of icon infiltration resin on postorthodontic white spot lesions
}

\author{
Angela Pia Cazzolla, ${ }^{1}$ Anna Rosa De Franco, ${ }^{2}$ Mariagrazia Lacaita, ${ }^{1}$ \\ Vitantonio Lacarbonara ${ }^{1}$
}

'Department of

Odontostomatology and

Surgery, Universita degli Studi di

Bari Aldo Moro, Bari, Italy

${ }^{2}$ Department of Clinical

Dentistry, Universita degli

Studi di Bari Dipartimento

Interdisciplinare di Medicina,

Bari, Italy

Correspondence to

Dr Angela Pia Cazzolla,

elicio@inwind.it

Accepted 28 June 2018

Check for updates

(c) BMJ Publishing Group Limited . Re-use permitted under CC BY-NC. No commercial re-use. See rights and permissions. Published by BMJ.

To cite: Cazzolla AP, De Franco AR, Lacaita M, et al. BMJ Case Rep Published Online First: [please include Day Month Year]. doi:10.1136/bcr-2018 225639

\section{SUMMARY}

White spot lesions are defined as enamel surface and sub surface demineralisation, although these lesions can be reversed and do not form cavities. Infiltration using fluid resin proved to be a valid micro-invasive alternative compared with traditional conservative therapy. This has allowed treatment without any trauma (no use of local anaesthesia and cavity preparation) of numerous lesions in only one session with stable clinical (mechanical stability, enamel hardness, conservation of sound tissue) and aesthetic results (disappearance of lesions) over the time. The present report evaluates the effectiveness of Icon infiltration resin on postorthodontic white spots at 6 months, 1 and 4 years.

\section{BACKGROUND}

White spot lesions (WSLs) are defined as enamel surface and subsurface demineralisation without cavitation. These manifestations represent the first clinical observation of the progression of dental caries with the possibility being reversed. These lesions are characterised by a white chalky, opaque appearance. It is possible to see WSLs in patients after fixed orthodontic treatment that make oral health difficult and increase risk of enamel demineralisation. ${ }^{1}$

The specific aspect of these lesions is due to an optical phenomenon, as demineralisation process causes an increase in the pore volume and the refractive index (RI) of the enamel changes because of air and water presence. There are predisposing risk factors such as poor oral hygiene, altered salivary flow and the presence or absence of fluoridation areas. In the literature, there is a WSLs incidence equal to $46 \%-73 \%$ in patients treated with fixed orthodontic therapy. ${ }^{2}$

The therapeutic approach changes on the basis of the different types of lesion: cavitated and non-cavitated. In the first case, a restorative approach is needed; on the contrary, in the second case, preventive therapies are useful. Several approaches have been proposed for the management of non-cavitated carious lesions: remineralisation of the lesion with topical fluoride application using fluoride rinses or fluoride varnishes with tri-calcium phosphate, ${ }^{3}$ casein phosphopeptide-amorphous calcium phosphate pastes (CPP-ACP) ${ }^{4}$ fluoride associated to CPP-ACP (Tooth Mousse- Mi Paste plus, GC, Tokyo, Japan); pastes made of hydroxyapatite, fluorine and xylitol (Remin-Pro, Voco Gmbh,
Cuxhaven, Germany), ${ }^{5}$ microabrasion with $18 \%$ hydrochloric acid and pumice. However, these treatment options have limitations as they do not give immediate result, require patient compliance and stain from external sources may get incorporated into lesions during remineralisation. Besides, remineralisation occurs only superficially, while the body lesions remain porous which explains the unpredictable results and persistence of whitish discolouration.

Infiltrating resinous polymers are considered as an 'ultra conservative' or 'non-invasive' approach.

The aim of this study was to assess the efficacy of treatment of WSLs with infiltrating resin (Icon, DMG, Hamburg, Germany) and to show clinical and aesthetic results in a patient affected by numerous WSLs, appearing after orthodontic treatment with follow-up at 6 months, 1 and 4 years.

\section{CASE PRESENTATION}

A 13-year-old boy, orthodontically treated, with fixed appliances for two and a half years, reported at the Department of Pediatric Dentistry, Clinic of Dentistry, University of Bari. On oral examination, the patient showed several ICDAS 2-3 WSLs on the following teeth: $1.1,1.2,1.3,1.4,1.5,2.1,2.2$, $2.3,2.4,2.5,3.1,3.2,3.3,3.5,4.2,4.3,4.4$ and 4.5. Considering the high number of lesions, a mini invasive therapeutic approach with infiltrating resin Icon (DMG, Hamburg, Germany) was preferred, applying DMG Icon caries infiltration vestibular resin, due to WSLs localisation.

\section{TREATMENT}

Icon resin consists of a kit containing three syringes: Icon-Etch, hydrochloric acid, pyrogenic silicon acid and surfactant based; Icon Dry, 99\% ethanol based and Icon infiltrant, that is the infiltrating methacrylate-based resin.

Before treating, teeth were cleaned with polish pastes (figure 1), rinsed again and the rubber dam was applied on them to protect soft tissue and achieve clean and dry working condition (figure 2). In the first step, after oral prophylaxis of teeth, the surface of the white spot was eroded by application of a $15 \%$ hydrochloric acid gel (Icon-Etch) for $2 \mathrm{~min}$. The etching procedure serves to remove superficial discolourations and the higher mineralised surface layer, which might hamper resin penetration. Acid was sucked and rinsed again for $30 \mathrm{~s}$; then the treated surfaces were dried. The lesion was 


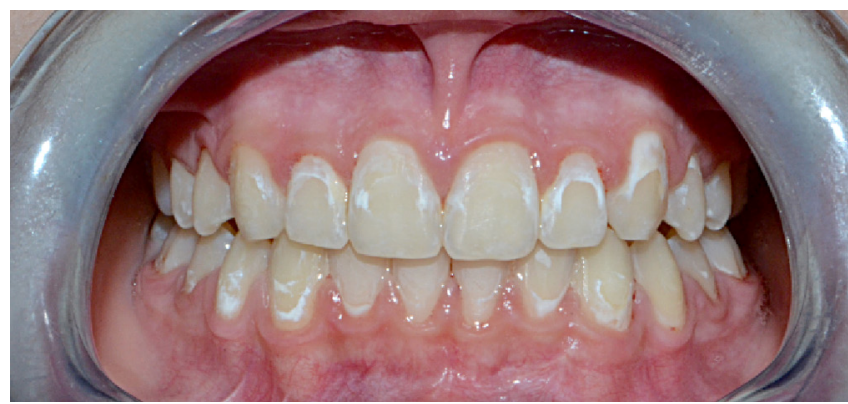

Figure 1 Preoperative picture showing numerous white spot lesions (WSLs) of upper and lower dental arch.

desiccated by applying ethanol (Icon-Dry) for 30 s followed by air drying. Dry solution provides a preview of the aesthetic result that could be expected after infiltration. Previous studies on the subject showed that frequency of etching intervals needs to be adjusted to the surface hardness and the depth of the WSLs. In this case, on the basis of the aesthetic outcomes obtained, etching was performed a second time for a further 2 min on deeper lesions on teeth 1.2, 2.2, 2.3, 2.4, 3.2, 3.3, 4.3 and 4.4.

In the last step, Icon infiltrant composed of tetraethylene glycol dimethacrylate was applied on the lesion surface using a microbrush and allowed to sit for 5 min.

The excess was removed using a cotton roll and, when necessary, using a dental floss. Then, Icon resin was light cured for $40 \mathrm{~s}$ with BA Optima 10 lamp. Finally, the rough surface was polished using disks and silicone polishers to avoid discolouration by food stains (figure $3 \mathrm{~A}-\mathrm{C}$ ).

\section{OUTCOME AND FOLLOW-UP}

The WLSs are not visible after the application of Icon. The patients reported no important adverse events or side effects during the 4-year period following infiltration.

Standardised digital photographs were taken four times: before treatment, 6 months after (figure 4), 1 year after (figure 5) and 4 years after treatment (figure 6). Before taking pictures, the assigned teeth were cleaned using pumice and rubber polishing cups. Clinical examination and photographs showed relevant optical harmonisation of infiltrated WSL with adjacent enamel and aesthetic stability in the time. Colour and lightness characteristics of the Icon infiltrant as well as the aesthetic camouflage effects were not altered significantly or clinically relevant after 4 years. Besides, there was no progression of early carious lesions with arrest of lesions.

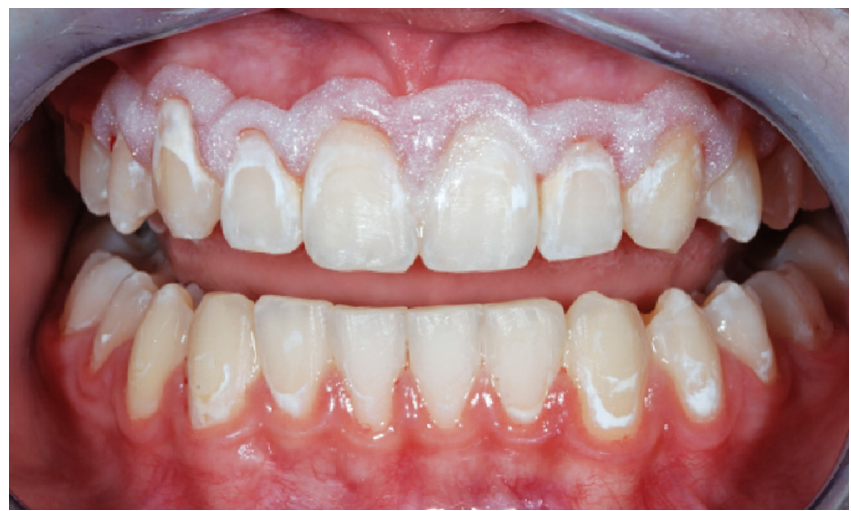

Figure 2 Application of rubber dam to protect soft tissue.

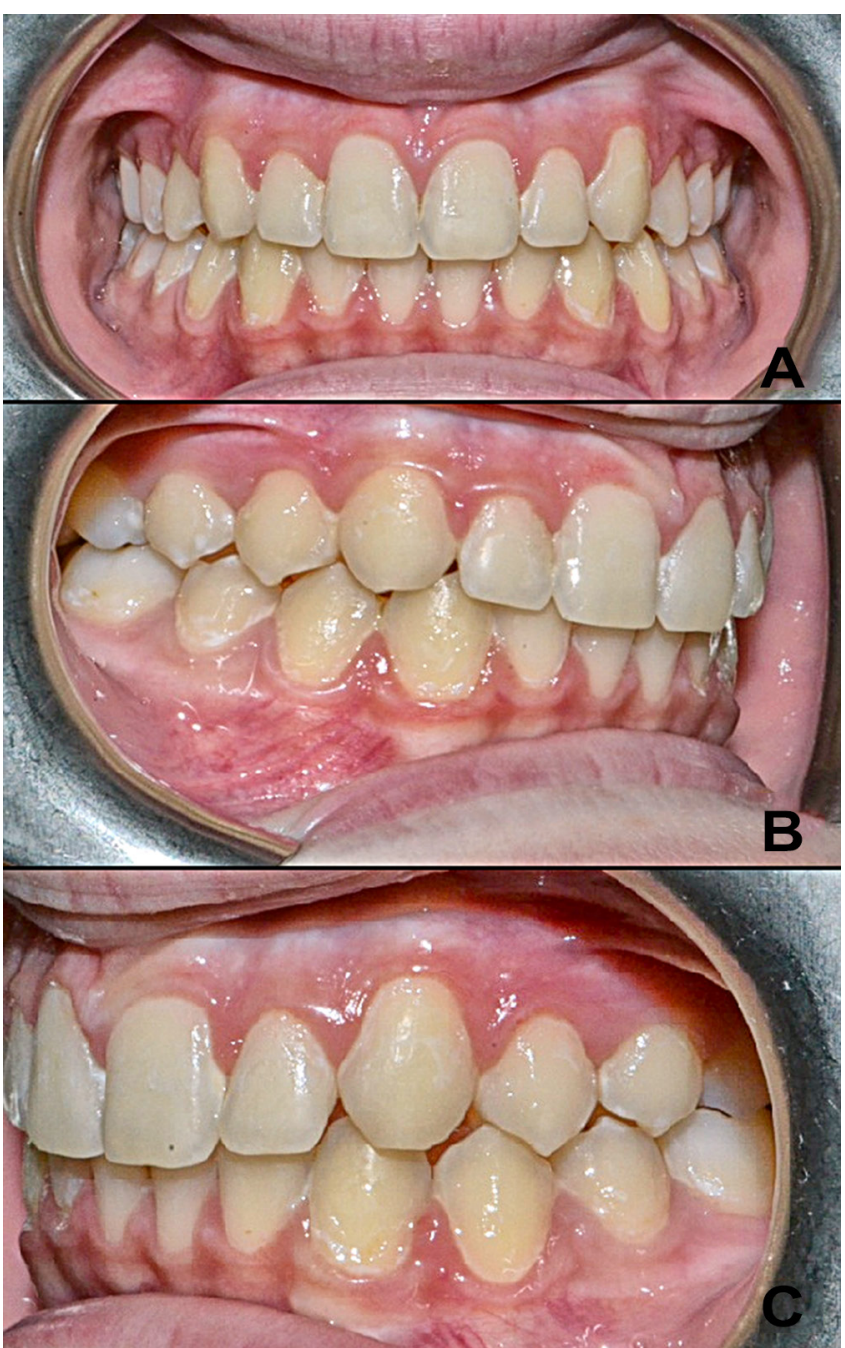

Figure 3 (A-C) Postoperative picture.

\section{DISCUSSION}

Enamel demineralisation and WSLs associated with orthodontic fixed appliances is one of the greatest challenges faced by clinicians at the end of the orthodontic treatment not only for aesthetic reasons but also because this subsurface demineralisation represents the first stage of caries formation. The etiopathogenesis of white spots is due to pathogenic bacteria which, infiltrating the surface of the enamel, produce organic acids capable of dissolving the calcium and phosphate ions of the dental structure, thus causing lesions. ${ }^{9}$

Usually, orthodontic patients have a significantly high incidence of WSLs compared with non- orthodontic patients and

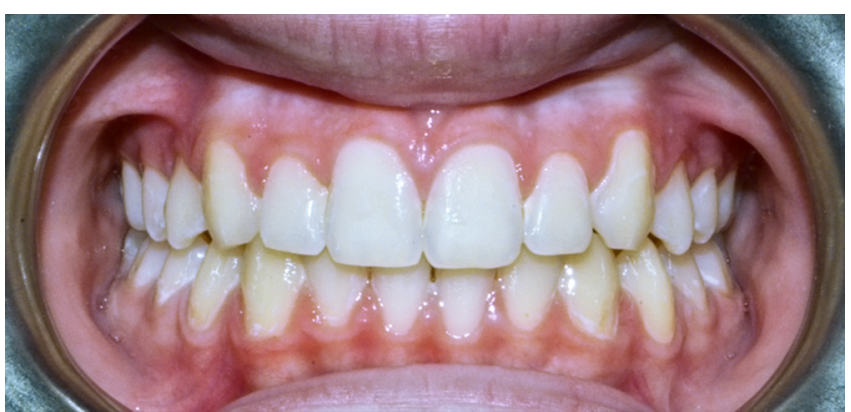

Figure 4 Six-month follow-up picture. 


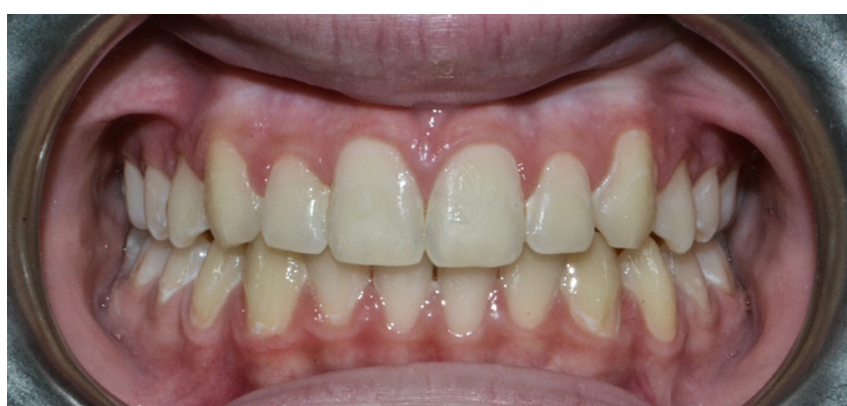

Figure 5 One-year follow-up picture.

may also exhibit aesthetic changes a few years after treatment. Early enamel lesions present an apparent intact layer followed by a subsurface porous area, called the body of the lesion. During demineralisation of the enamel, the pore volume of the WSLs increases, and hence, the RI of the lesions can be altered by light scattering. The microporosities of enamel caries are filled with either a watery medium or air. Due to the difference between the RI of sound enamel (RI: 1, 62) and water (RI: 1,33) or air (RI: 1.0) within the body of a lesion, ambient light which shines on the teeth is deflected and scattered, making the initial carious lesions appear as a clinically visible opacity especially when desiccated. ${ }^{10}$

WSLs enter in differential diagnosis with non-carious WSLs, classified as fluorosis, developmental enamel hypomineralisation, molar incisor hypomineralisation, hypomineralisation of traumatic origin and enamel hypoplasia, which can have genetic and environmental bases or are associated with rare diseases. ${ }^{11-14}$

These non-carious white spots are usually limited to a few teeth (typically, anterior teeth) or generalised throughout dentition, covering the entire tooth surfaces, and are not associated with orthodontic brackets or bands.

Although the therapeutic approaches reported in the literature are multiple, the new guidelines are focused on 'non-invasive treatments. 1516

Among the commercially available materials, in this study, we tested Icon (DMG, Hamburg, Germany), a methacrylate resin with an infiltrating power. Icon is usable both for superficial and vestibular caries. Infiltrating for superficial caries can be applied for carious lesions with a severity no greater than D1*, where there may be difficulties in operating procedures. Infiltrating for vestibular caries is suitable for WSLs, in particular, in those patients treated with a fixed orthodontic therapy. Originally, the aim of this treatment was to prevent further progression of early carious lesions by occluding pores of the lesion body, which acts as a cariogenic acid pathway. The very low viscosity resin, referred to as 'infiltrant,' acts by occluding the pores of the lesion body by capillary forces ${ }^{17}$ and when the pores are filled with

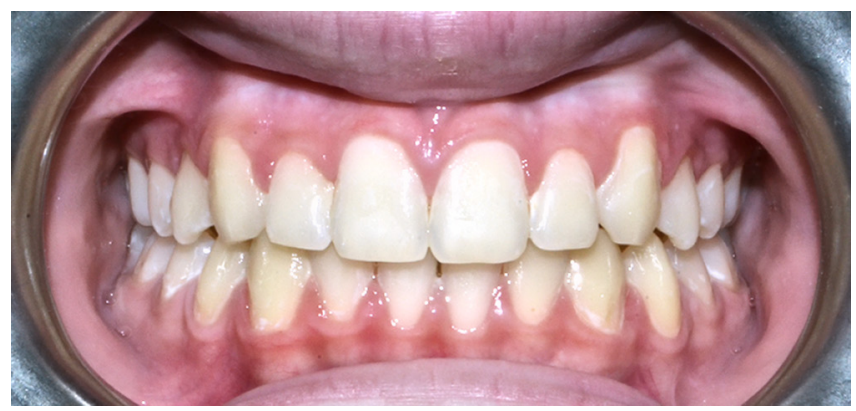

Figure 6 Four-year follow-up picture. the infiltrant, the infiltrated WSLs appear to be similar to the surrounding sound enamel because of the negligible difference in the refractive indices between the sound enamel $(R I=1.62)$ and the infiltrant $(\mathrm{RI}=1.46) .{ }^{18}$

Therefore, if the pores of the lesion body can be completely occluded with the infiltrant, the progression of the WSLs can be prevented and the aesthetic issues can also be resolved. ${ }^{19}$

Spectrophotometric studies with crystal eye spectrophotometer show that the use of Icon results in a relevant increase in the values analysed, that is $\mathrm{L}^{*}$ (difference of lightness), $\mathrm{A}^{*}$ (green-red coordinate) and $\mathrm{B}^{*}$ (blue-yellow coordinate). ${ }^{20}$

In vitro studies show how the Icon resin significantly increases the micro hardness of the enamel, as the penetration power in structures is $67.14 \%$ compared, for example, to other materials, such as colloidal silica, whose percentage is $54.53 \%$. These values can also be found in studies with confocal microscopy and through Vickers micro hardness testing (Series 400, Wilson Wolpert, Germany). ${ }^{21}$

In the literature, it has been shown that the use of infiltrating resin is effective in the prevention and care of initial interproximal lesions. In adolescent patients with initial, non-cavitated carious lesions, the marginal infiltrator used reduced lesions progression with satisfactory results. The 4-year follow-up has shown that such a therapeutic approach is effective and lasting. ${ }^{22}$

The Icon resin also applies to orthodontic therapies with the aim of improving or blocking white enamel lesions on dental elements where an orthodontic band is to be applied. The infiltration of low viscosity light curing resin into the subsurface lesion is an intermediary treatment between preventive and restorative therapy for the arrest of carious lesion, leading to the arrest of caries progression ${ }^{23}$ and aesthetic improvement. ${ }^{24}$

The infiltration of the resin of porous lesion structures could mechanically strengthen the lesion, helping to prevent the formation of caries and it also blocks the further introduction of any nutrition into the porous system. In addition, this method can be used with patients with a known fluoride sensitivity. $^{2526}$

Several short-term studies, in vitro research and case reports have been conducted but case reports with a large number of involved teeth by WSLs and with a 4-year follow-up are not described. The results showed sufficient durability over 4 years and clinical and aesthetic results stable at 3 and 6 months, 1 and 4 years. The resin infiltration technique demonstrated having several advantages: mechanical stabilisation of demineralised enamel, maintenance of sound hard substance, permanent closure of surface micropores, obturation of porous and deeply demineralised areas, inhibition of lesion progression by increasing resistance to demineralisation and high patient

\section{Learning points}

- The use of infiltrating resins prove to be an efficient microinvasive treatment for white spot lesions (WSLs), allowing to treat lesions in a single and non-traumatic session.

- The optical appearance of WSL was improved by lesion infiltration.

- The results achieved with Icon were stable over a period of 4 years in vivo.

- The patient reported no important adverse events or side effects during the 4-year period following infiltration. 
compliance. Therefore, this treatment seems to fill the 'treatment gap' between non-invasive and invasive interventions for WSLs.

Contributors APC designed and performed the study. ARDF wrote the manuscript. $M L$ analysed the data. VL supervised the project.

Funding The authors have not declared a specific grant for this research from any funding agency in the public, commercial or not-for-profit sectors.

Competing interests None declared.

Patient consent Parental/guardian consent obtained.

Provenance and peer review Not commissioned; externally peer reviewed.

Open access This is an open access article distributed in accordance with the Creative Commons Attribution Non Commercial (CC BY-NC 4.0) license, which permits others to distribute, remix, adapt, build upon this work non-commercially, and license their derivative works on different terms, provided the original work is properly cited, appropriate credit is given, any changes made indicated, and the use is non-commercial. See: http://creativecommons.org/licenses/by-nc/4.0/.

\section{REFERENCES}

1 Paula AB, Fernandes AR, Coelho AS, et al. Therapies for white spot lesions-a systematic review. J Evid Based Dent Pract 2017;17:23-38.

2 Eckstein A, Helms HJ, Knösel M. Camouflage effects following resin infiltration of postorthodontic white-spot lesions in vivo: One-year follow-up. Angle Orthod 2015;85:374-80.

3 Cury JA, Tenuta LM. Enamel remineralization: controlling the caries disease or treating early caries lesions? Braz Oral Res 2009;23 Suppl 1(Suppl 1):23-30.

4 Cochrane NJ, Shen P, Byrne SJ, et al. Remineralisation by chewing sugar-free gums in a randomised, controlled in situ trial including dietary intake and gauze to promote plaque formation. Caries Res 2012;46:147-55.

5 Ebrahimi M, Mehrabkhani M, Ahrari F, et al. The effects of three remineralizing agents on regression of white spot lesions in children: A two-week, single-blind, randomized clinical trial. J Clin Exp Dent 2017:9:e641-e8.

6 Zawaideh Fl. Resin infiltration technique : a new era in caries management. Smile Dental Journal 2014:9:22-7.

7 Knösel M, Eckstein A, Helms HJ. Durability of esthetic improvement following Icon resin infiltration of multibracket-induced white spot lesions compared with no therapy over 6 months: a single-center, split-mouth, randomized clinical trial. Am J Orthod Dentofacial Orthop 2013;144:86-96.

8 Paris S, Meyer-Lueckel H. Masking of labial enamel white spot lesions by resin infiltration--a clinical report. Quintessence Int 2009;40:713-8.

9 Shivanna V, Shivakumar B. Novel treatment of white spot lesions: a report of two cases. J Conserv Dent 2011;14:423-6.
10 Gugnani N, Pandit IK, Gupta M, et al. Caries infiltration of noncavitated white spot lesions: A novel approach for immediate esthetic improvement. Contemp Clin Dent 2012;3(Suppl 2):199-202.

11 Cazzolla AP, Troiano G, Zhurakivska K, et al. Langerhans cell histiocytosis of the maxillae in a child treated only with chemotherapy: a case report. J Med Case Rep 2017:11:130.

12 Favia G, Lacaita MG, Limongelli L, et al. Hyperphosphatemic familial tumoral calcinosis: odontostomatologic management and pathological features. Am I Case Rep 2014;15:569-75.

13 Lacarbonara M, Cazzolla AP, Lacarbonara VA, et al. Prolidase deficiency: dento-facial aspects in a paediatric patient. Eur J Paediatr Dent 2014;15(2 Suppl):224-8.

14 Majorana A, Bardellini E, Brunelli PC, et al. Dentinogenesis imperfecta in children with osteogenesis imperfecta: a clinical and ultrastructural study. Int J Paediatr Dent 2010:20:112-8.

15 Akin M, Basciftci FA. Can white spot lesions be treated effectively? Angle Orthod 2012:82:770-5.

16 Skucha-Nowak M, Machorowska-Pieniążek A, Tanasiewicz M. Assessing the penetrating abilities of experimental preparation with dental infiltrant features using optical microscope: preliminary study. Adv Clin Exp Med 2016:25:961-9.

17 Paris S, Meyer-Lueckel H. Infiltrants inhibit progression of natural caries lesions in vitro. J Dent Res 2010;89:1276-80.

18 Neuhaus KW, Graf M, Lussi A, et al. Late infiltration of post-orthodontic white spot lesions. J Orofac Orthop 2010;71:442-7.

19 Ekizer A, Zorba YO, Uysal T, et al. Effects of demineralizaton-inhibition procedures on the bond strength of brackets bonded to demineralized enamel surface. Korean J Orthod 2012;42:17-22

20 Yuan $\mathrm{H}$, Li J, Chen L, et al. Esthetic comparison of white-spot lesion treatment modalities using spectrometry and fluorescence. Angle Orthod 2014;84:343-9.

21 Mandava J, Reddy YS, Kantheti S, et al. Microhardness and penetration of artificia white spot lesions treated with resin or colloidal silica infiltration. J Clin Diagn Res 2017:11:ZC142-ZC6

22 Caglar E, Kuscu 00, Hysi D. Four year evaluation of proximal resin infiltration in adolescents. Acta Stomatol Croat 2015:49:304-8.

23 Taher NM, Alkhamis HA, Dowaidi SM. The influence of resin infiltration system on enamel microhardness and surface roughness: An in vitro study. Saudi Dent $J$ 2012;24:79-84.

24 Meyer-Lueckel H, Paris S. Improved resin infiltration of natural caries lesions. J Dent Res 2008;87:1112-6.

25 Aziznezhad M, Alaghemand H, Shahande Z, et al. Comparison of the effect of resin infiltrant, fluoride varnish, and nano-hydroxy apatite paste on surface hardness and streptococcus mutans adhesion to artificial enamel lesions. Electron Physician 2017:9:3934-42.

26 Kumar H, Palamara JEA, Burrow MF, et al. An investigation into the effect of a resin infiltrant on the micromechanical properties of hypomineralised enamel. Int J Paediatr Dent 2017;27:399-411.

Copyright 2018 BMJ Publishing Group. All rights reserved. For permission to reuse any of this content visit http://group.bmj.com/group/rights-licensing/permissions.

BMJ Case Report Fellows may re-use this article for personal use and teaching without any further permission

Become a Fellow of BMJ Case Reports today and you can:

- Submit as many cases as you like

- Enjoy fast sympathetic peer review and rapid publication of accepted articles

- Access all the published articles

Re-use any of the published material for personal use and teaching without further permission

For information on Institutional Fellowships contact consortiasales@bmjgroup.com

Visit casereports.bmj.com for more articles like this and to become a Fellow 